\title{
SOLID STATE VOLTAMMETRY AND SENSORS IN SOLIDS AND GASES
}

\author{
Performance Report
}

April 1991 to March 1992

\author{
Royce W. Murray \\ Renan Laboratories of Chemistry \\ University of North Carolina \\ at Chapel Hill
}

Chapel Hill, NC 27599-3290

April 1992

\section{PREPARED FOR THE U.S. DEPARTMENT OF ENERGY UNDER GRANT NUMBER DE/FG05-87ER13675}

\section{DISCLAIMER}

\begin{abstract}
This report was prepared as an account of work sponsored by an agency of the Uinited States Government. Neither the United States Government nor any agency thereof, nor any of their employees, makes any warranty, express or implied, or assumes any legal liability or responsibility for the accuracy, completeness, or usefulness of any information, apparatus, product, or process disclosed, or represents that its use would not infringe privately owned rights. Reference herein to any specific commercial product, process, or service by trade name, trademark, manufacturer, or otherwise does not necessarily constitute or imply its endorsement, iecommendation, or favoring by the United States Government or any agency thereof. The visws and opinions of authors expressed herein do not necessarily state or reflect those of the United States Government or any agency thereof.
\end{abstract}




\section{PERFORMANCE REPORT FOR 4/1/91 TO 3/31/92}

This project explores the electrochemical reactivity of electron transfer donor/acceptors dissolved in and diffusing through solid and semi-solid, ionically conductive media. The emphasis is on developing voltammetric experiments that are quantitatively interpretable in terms of the mass transport and electron transfer rates and thermodynamic equilibria of the redox solutes, and to exploit such experiments to probe their chemical and electrochemical behavior in the solid media. Techniques for quantitative voltammetry in solids were essentially unknown prior to initiation of this DOE project.

We mainly employ poly(ether)s containing dissolved metal salts electrolytes ("polymer electrolytes"), as prototype solid and semi-solid solvents.

During this award year we have (a) concluded a study of plasticization chemistry in poly (ether) polymer electrolytes, made progress in devising techniques for measuring the rates of electron transfer reactions in solid and semi-solid poly(ether)s, (c) continued efforts to design and understand the behavior of microband electrodes of various widths $(0.1$ to $10 \mu \mathrm{m})$ in voltammetry of redox solutes, and (d) initiated synthetic efforts to attach ethylene oxide chains of various lengths to redox solutes.

since the previous Report, five papers listed as in press or submitted have appeared, and three additional papers are currently either in press or submitted. These are listed under publications. Experimental work for several other papers are complete; these "in preparation" papers are indicated below and are not 1 isted under publications.

\section{DESIGN OF ELECTROCHEMICAL MICROCELLS AND EXPERIMENTS FOR SOLID STATE VOLTAMMETRY}

Because this is the first work in quantitative solid state voltammetry seeking to quantitatively interpret currentpotential-time data, an important research element is improvement of our measurement tools. Microelectrode-based experiments have been most successful, being more tolerant to the mediocre ionic conductivities of the typical polymer electrolyte. At macrosized electrodes low conductivities lead to loss of quantitative electrode potential control.

Interdigitated Array Microelectrodes. Experiments were carried out using microlithographically-defined microelectrode arrays consisting of 25 parallel Au strips separated by $15 \mu \mathrm{m}$ gaps, coated with a polymer electrolyte solution containing equal 
amounts of electron donor DON and acceptor ACC of a redox couple pair. Under inert gas and anhydrous conditions, application of a $\Delta \mathrm{E}$ across the electrodes yields after a diffusion time interval, linear concentration gradients of DON and ACC across the interelectrode gap and a steady current that is proportional to the diffusion coefficient $D_{A P P}$ of DON and ACC (assumed equal). The $D_{\text {APp }}$ values are obtained from a limiting current plateau and are not perturbed by resistance effects.

We thereby measured $D_{A P p}$ for several DON/ACC couples (ferrocenes, TCNQ, TCNE, DDQ, etc) over a range of concentrations. We found that $D_{A P P}$ of redox couples having intrinsically large self exchange rate constants and at lower concentrations, increased with concentration consistent with coupling between physical diffusion of DON and ACC and fast electron hopping reactions between them. At larger concentrations, and for couples with small $k_{E x}$ values, often $D_{A P P}$ shows an opposite (decreasing) trend with concentration because of overwhelming concentration-dependent changes in physical

diffusion rates. These data show that redox couple diffusicn in polymers can provide, under well-chosen circumstances, an avenue to study of solid state electron transfer dynamics.

We also discovered during the IDA studies that $D_{A P P}$ is extremely sensitive to the dynamics of phase-change events (e.g., microcrystallization) in the polymer phase host. Sudden crystallizations (reflected in abrupt changes in diffusion constants) were detected as long as 24 hours following a thermal melt-quench cycle. Poly(ether) crystallization is well-known, but there is little previous information on its dynamics; our experiment opens a convenient avenue to its study.

This work was written up in publication \#A.

Microband Electrodes. As explained in last year's Report, we are interested in microband electrodes for use in polymer solvents that are particularly resistive and in which redox solutes exhibit extremely slow diffusion rates. The currents from microdisk electrodes under such circumstances dip to below 1 $\mathrm{pA}$ and become difficult to measure. We set out to evaluate theoretical predictions about microband electrodes as used under radial and linear diffusion conditions, and to compare these to analogous predictions about microdisk electrodes. The study has required fabricating microband electrodes (the edges of thin metal films bounded by insulating support) over the $100 \mathrm{NM}$ to 10 $\mu \mathrm{m}$ range, that have an exactly defined width and length and whose exposed surfaces lie exactly in-plane with the insulating supports with no steps or gaps at the metal film-insulator boundary. We have found it relatively easy to produce microband electrodes that behave well under radial diffusion conditions, but the same electrodes produce currents that are larger than expected (from their nominal dimensions) under linear diffusion 
conditions. 'The deviations arise from the difficulty of fabricating thin metal edges perfectly bounded by insulator, with no steps or gaps, which increase the electrode area. The fabrication problem has been difficult; the key seems to be adhesion at the metal/insulator boundary. The most promising technique presently involves coating a glass slide with a Au film, chemically bonding an adhesion layer to the Au surface, coating it with a epoxy layer, lifting the epoxy/Au film off the glass slide, and repeating the adhesion layer-epoxy coat on the other Au side.

These results show that some of the existing microband literature (and potentially some of the microdisk and nanodisk literature) may be in error since in all cases prior to our study the evaluation of the electrode (in other laboratories) has involved radial diffusion conditions. We see the slow diffusion realm of solid state voltammetry as a major one when we proceed to other polymers than the poly(ether)s, and the microband technique will be an important tool therein. For these two reasons we have been slow to publish these results, waiting until we have more ideal fabrication procedures in hand. Hopefully we will be writing them up during the coming year.

AC Voltammetry. The results of our first microdisk AC voltammetric studies have appeared (publication \#14). A new student ( $R$. Pyati) is now setting up a different type of $A C$ phase-amplitude measurement, based on newly acquired lock-in amplifier-based equipment. We are still in the teething stage with this equipment, which should be more sensitive to heterogeneous electron transfer rate constant values than the previous apparatus. The immediate objective is to evaluate the monomer solvent dependence of the rate constant of the DON/ACC couple $\left[\mathrm{Co}(\mathrm{bpy})_{3}\right]^{3++2^{+}}$couple, in order to evaluate this couple as a suitable probe to detect polymer solvent dynamical rate effects, as was hypothesized in publication \#14.

\section{ELECTRON TRANSFER DYNAMICS}

We have now a significant array of metrods (three) to measure electron transfer rates in poly(ether) solvents.

Method \#1 employs a metal complex with a slow heterogeneous rate constant and an outer sphere electron transfer mechanism; $\left[\mathrm{Co}(\mathrm{bpy})_{3}\right]^{3+}$ couple is the proposed example. We have applied AC voltammetry to study its electron transfer rate at a Pt microdisk (publication \#14) but as noted above we are (in current work) aiming to validate the outer sphere character of the co couple in monomer solvents, in order to be able to interpret its rate behavior in the context of polymer solvent dynamics. 
Method \#2 employs a redox couple with an extremely large $k_{E X}$, under conditions of slow diffusion in the polymer solvent, so that the electron transfer kinetics show up in an enhanced diffusion rate (coupled diffusion, see apove). We have been successful in doing this with the TCNQ/-T couple (publication \#16), and in the past year finished and submitted for publication (\#B) a further study of this couple that contains important, new observations about the nature of electron transfers during coupled diffusion. In short, when electron transfer is fast yet diffusion is slow, the electron transfer may occur at larger than contact distances. If diffusion becomes faster, electron transfers occur at shorter distances. This forces a correlation between the physical diffusion and electron transfer rates that has not heretofore been seen in solid state chemistry. Our data, and the correlation, cover a $10^{5}$ range, so the effect can be a very strong one. We have submitted this for publication (\#B).

A new doctoral student has taken up this project and is searching for other examples of the long range electron transfer effect. The measurements have been based on potential step chronoamperometry at microdisks; we will also explore alternative transport-rate methodology.

Method \#3 involves use of a polymerized os bpy complex, coated on the electrode, at which an up-hill electron crossreaction occurs with another metal complex dissolved in the contacting (monomer or polymer) solvent. This allows normally fast electron transfer systems to be studied with a slow technique (steady state microelectrode voltammetry). We have demonstrated that one example of this kind of reaction follows classical monomer solvent dynamical theory (publication \#17), and in the past year extended this study by modifying the poly(ether) solvent in ways calculated to alter the poly (ether) chain dynamics. Indeed when we increase the electrolyte concentration, the poly(ether) chain length, or the electrolyte ion crosslinking interaction with the poly (ether) chain, the physical diffusion rate of the metal complex diminishes as expected for slow segmental chain motions (antecedent to diffusive solute motions). Tightly correlated with these changes, we see changes in the electron transfer cross-reaction rate. We take these results as encouraging evidence that we will be able to use this electron transfer rate effect tactic as a probe of the dipolar fluctuations within solvent media and thus of sub-segmental polymer chain motions (timescales are 5-25 psec according to these results). Such very fast motions have not been detected before, even slower ones are currently hard to study, with various forms of acoustical spectroscopy.

The second phase of the method 3 study is essentially complete and will be soon written up for publication. 


\section{ELECTROCHEMICAL GAS CHROMATOGRAPHY DETECTOR AND POLY(ETHER) PLASTICIZATION}

As described previously (publication \#7,8,15), sorption of small organic volatiles into poly(ether) films on electrodes produces an increase in the transport rates of eiectrolytes and of redox molecules dissolved therein, that can be detected (transiently if desired) by changes in the voltammetric current at the electrode.' We have referred to this transport-enhancement effect as diffusion-plasticization, and found it interesting to try to shed some light on its molecular basis. That is, what kind of molecular interactions occur to produce the increased transport rate? Plasticization is of enormous technological importance, and appears in many forms (mechanical as well as transport-based), but its molecular understanding in the literature seems scant.

During the past year, we carried out a study attempting to correlate the size of the formation constant $K_{F o R}$ between the electrolyte cation and the sorbed organic volatile, with the size of the corresponding enhancement of the ionic conductivity of the electrolyte. The hypothesis behind the experiment is that the electrolyte cation is a cross-link agent in the poly(ether) solvent so that its transport rate is associated with its coordination by the poly (ether) dipoles. The sorbed organic coordinates the cation, freeing it for faster transport (and larger ionic conductivity). We choose a $\mathrm{Zn}^{2+}$ electrolyte, seeking a strong coordination effect.

The $\mathrm{K}_{\mathrm{FOR}}$ of $\mathrm{Zn}^{2+}$ with sorbed organics (nitriles, alcohols, methylbenzenes) was measured from the retention times of these organics in a GC column in which the $\mathrm{zn}$ /polymer electrolyte was used as the stationary phase (inverse gas chromatography), and changes of ionic conductivity of the $\mathrm{zn}$ electrolyte measured were under analogous conditions. While a correlation between $\mathrm{K}_{\mathrm{FoR}}$ values and $\Delta \sigma$ values was present, the range of variation was not very great. This was the first of this kind of study, so we think we can do a better job now of choosing chemical examples to explore the hypothesis in future experiments. This study will be written up during the year.

\section{POLYMER SOLVENTS}

We have accumulated a great deal of experimental information on the properties of poly (ether) solvents that pertain to their usefulness in solid state voltammetry studies. We collected this together in publication \#C. 


\section{SYNTHESIS}

The redox molecule size and strength of interaction with polymer solvent appear to be important determinants of their diffusion rates in solid state solvents, e.g., the poly(ether)s. Also of interest is the behavior of redox couples that have poly (ether) tails and resemble their poly(ether) solvent hosts. In order to better investigate these subjects, and some others, we have committed some effort over the pst year in design and synthesis of redox couples with attached ethylene oxide tails. For example, we have prepared

$$
\mathrm{CH}_{3} \mathrm{OCH}_{2} \mathrm{CH}_{2} \mathrm{OCH}_{2} \mathrm{CH}_{2} \mathrm{OCH} \mathrm{CpFeCpCH}_{2} \mathrm{OCH}_{2} \mathrm{CH}_{2} \mathrm{OCH}_{2} \mathrm{CH}_{2} \mathrm{OCH}_{3}
$$

This molecule (I) is similar in dimensions to the poly (ether) $\mathrm{CH}_{3}\left(\mathrm{OCH}_{2} \mathrm{CH}_{2}\right)_{9} \mathrm{OCH}_{3}$ and is miscible with it in all proportions. I also dissolves electrolyte itself, so it is possible to carry out voltammetry in it as an undiluted, ca. $2 \underline{M}$ concentration, electroactive linear polymer. We are evolving a number of analogous electroactive poly(ethers) and evaluating their electrochemical properties.

\section{PUBLICATIONS}

For the convenience of the Program officers, this is a complete listing of our publications under DOE support on the project on solid state voltammetry. The marked publications have appeared or seen some other activity during the Progress Report year. Publications which are still in the writing are mentioned above and are not listed.

1. Solid state Voltammetry of Electroactive Couples in Polyethylene Oxide Films on Microelectrodes, R. A. Reed, L. Geng, and R. W. Murray, J. Electroanal. Chem., 1986, 185, 208.

2. Solid state Linear Sweep Voltammetric Current Responses of Thin Films on Microdisk Electrodes. A Probe of Diffusion in Polymer Ion Conductors, R. A. Reed, L. Geng, M. Longmire, and R. W. Murray, J. Phys. Chem. 1987, 91, 2908.

3. Solid-State Voltammetry in a Three Electrode Electrochemical Cell-on-a-Chip with a Microlithographically Defined

Microelectrode, M. Moxita, M. L. Longmire and R. W. Murray, Anal. Chem. 1988, 60, 2770 .

4. Chemical Phenomena in Solid state Voltammetry in Polymer Solvents, L. Geng, R. A. Reed, M-H. Kim, T. T. Wooster, B. N. Oliver, J. Egekeze, R. T. Kennedy, J. W. Jorgenson, J. F. Parcher and R. W. Murray, J. Am. Chem. Soc. 1989, 111, 1614 
5. Solid state Voltammetric Measurement of Plasticization Enhancement in Ionically conducting Polyethylene oxide Films, L. Geng, M. Longmire, R. A. Reed, J. F. Parcher, C. J. Barbour, and R. W. Murray, Chem. of Mats. 1989, 1, 58 .

6. Solid state Voltammetry in Ionically Conducting PhosphazeneLiSO $_{3} \mathrm{CF}_{3}$ Films, R. A. Reed, T. T. Wooster, D. R. Yaniv, J. S. Tonge, D. F. Shriver, and R. W. Murray, J. Electrochem. Soc. $1989, \underline{136}, 2565$.

7. Solid-State Voltammetry and Polymer Electrolyte Plasticization as a Basis for an Electrochemical Gas Chromatographic Detector, J. F. Parcher, C. J. Barbour, and R. W. Murray, Anal. Chem. 1989, 61, 584.

8. W. Dexi, H. Song, J. F. Parcher, R. W. Murray, Chromatographic Investigation of the structure, Crystallinity, and Complexation of the Conducting Polymer $\mathrm{P}(\mathrm{EO})_{x} / \mathrm{LiCF}_{3} \mathrm{SO}_{3}$, Chem. of Mats. 1989, 1 , 357 .

9. Voltammetric Measurement of Ultraslow Diffusion Rates in Polymeric Media with Microdisk Electrodes, M. L. Longmire, M. Watanabe, H. Zhang, T. T. Wooster, and R. W. Murray, Anal. Chem., $1990, \underline{62}, 747$.

10. A study of Ferrocene Diffusion Dynamics in Network Poly (ethylene oxide) Polymer Electrolyte by solid state Voltammetry, M. Watanabe, M. L. Longmire and R. W. Murray, J. Phys. Chem., 94, 1990, 2614.

11. Solid state Voltammetry and Self-Diffusion Dynamics of a Linear Monotagged Redox Polymer: Ferrocene Methoxy Poly(ethylene oxide), M. J. Pinkerton, Y. Le Mest, H. Zhang, M. Watanabe, and R. W. Murray, J. Amer. Chem. Soc., 1990, 112, 3730 .

12. Electron Self Exchange Dynamics Between Redox Sites in Polymers, N. Surridge, J. C. Jernigan, F. Dalton, R. P. Buck, M. Watanabe, T. T. Wooster, H. Zhang, M. Pinkerton, T. T. Wooster, M. L. Longmire, J. S. Facci, and Royce W. Murray, Royal society Medal Award Lecture, oxford University, Far. Disc. Chem. Soc., $88,1990,1$.

13. Polymer Electrolytes and Microelectrodes, M. Watanabe, M. Longmire, T. T. Wooster, H. Zhang, C. Barbour, and Royce W. Murray, NATO Advanced Study Institute on Microelectrodes: Theory and Applications, May, 1990, Kluwer Academic Publishers. NY, 1991, pp. 377-392。

14. Diffusion and Heterogeneous Electron Transfer Rates in Acetonitrile and in Poly-ether Polymer Melts by Alternating current voltammetry at Microdisk Electrodes, T. T. Wooster, M. L. 
Longmire, M. Watanabe, and Royce W. Murray, J. Phys. Chem. 1991, $\underline{95}, 5315$.

15. Theory for the Sensitivity and selectivity of a Polymer Diffusion Plasticization Based Solid state Electrochemical Gas Chromatography Detector, Carleton J. Barbour, Jon F. Parcher, and Royce W. Murray, Anal. Chem. 1991, 63, 604.

16. Electron Self Exchange Reactions in Solid state Voltammetry. LiTCNQ in Polymer Electrolytes, Part I. M. Watanabe, T. T. Wooster and Royce W. Murray, J. Phys. Chem., 1991, 95, 4573.

17. Monomer and Polymer Solvent Dynamic Control of an Electron Transfer Cross-reaction Rate at a Redox Polymer/Solution Interface, H. Zhang and R. W. Murray, J. Am. Chem. Soc. 1991, 113, 5183 .

IN PRESS

**A. Interdigitated Array Electrode Diffusion Measurements in Donor-Acceptor Solutions in Polyether Electrolyte Solvents, $\mathrm{H}$. Nishihara, F. Dalton, and Royce W. Murray, Ana.l. Chem., in press.

SUBMITTED

**B. Evidence for Long Range Electron Transfers Between Very Slowly Diffusing Tetracyanoquinodimethane and Its Radical Anions in Poly(ether) Solutions, T. T. Wooster, M. Watanabe, and Royce W. Murray, submitted for publication.

**C. Experimental Aspects of Solid State Voltammetry, M. L. Longmire, M. Watanabe, H. Zhang, T. T. Wooster, R. W. Murray, submitted for publication.

\section{BRIEF PLANS FOR NEXT YEAR}

Most of the following are commented on in the Performine Report, in context with on-going progress.

a) We will continue evaluation of microbands in solid state voltammetry aiming at finding reliable fabrication techniques and a correlation to current and resistance theory. Microbands will be applied to examples of very slow redox solute diffusion in polymer solids.

b) We will continue to explore microelectrode Method's 1 (with AC voltammetry) and 2 (with potential step voltammetry) for 
electron transfer dynamics, the goal being both to improve the methods and to expand our basic understanding of electron

transfers of very slowly diffusing reactants.

c) We will continue synthetic efforts to develop a family of redox labelled poly (ether)s and to understand their transport and electron transfer behavior including linear polymer selfdiffusion.

d) It is time that we explore other polymeric media for solid state experiments, and sometime during the year we will launch some scouting experiments. The significance is: how generally applicable to solid polymers are the ideas that we have developed for the poly(ether)s?

\section{OTHER SUPPORT}

National Science Foundation, Division of Chemistry, Chemical and Spatial Design of Electroactive Polymer Films on Electrodes, $\$ 224,000$ Jan 1, 1991-Dec. 31, 1991, fourth year award of three year continuing grant followed by two year Creativity Extension.

Office of Naval Research, Design and Application of Spatially Structured Polymer Coated Electrodes, \$306,000, october 1, 1989Sept. 30, 1992 (three year budget)

National Science Foundation Materials Chemistry Initiative, Design and Characterization of Molecular Films, Feb. 1, 1990January 31, 1993, (three year budget), \$550,000, co-investigators E. Irene (Dept. of Chemistry) and M. Silver (Dept. of Physics).

Pending: None other than this continuation.

\section{OTHER MATTERS}

In January 1991, the Principal Investigator began a five year term as the Editor of the American Chemical Society journal Analytical Chemistry. In April 1991 he received the ACS Analytical Chemistry Award at the national meeting of that society. In April 1991 he was elected to the National Academy of Sciences. These recognitions are in part owing to the research that has been done under DOE sponsorship. 

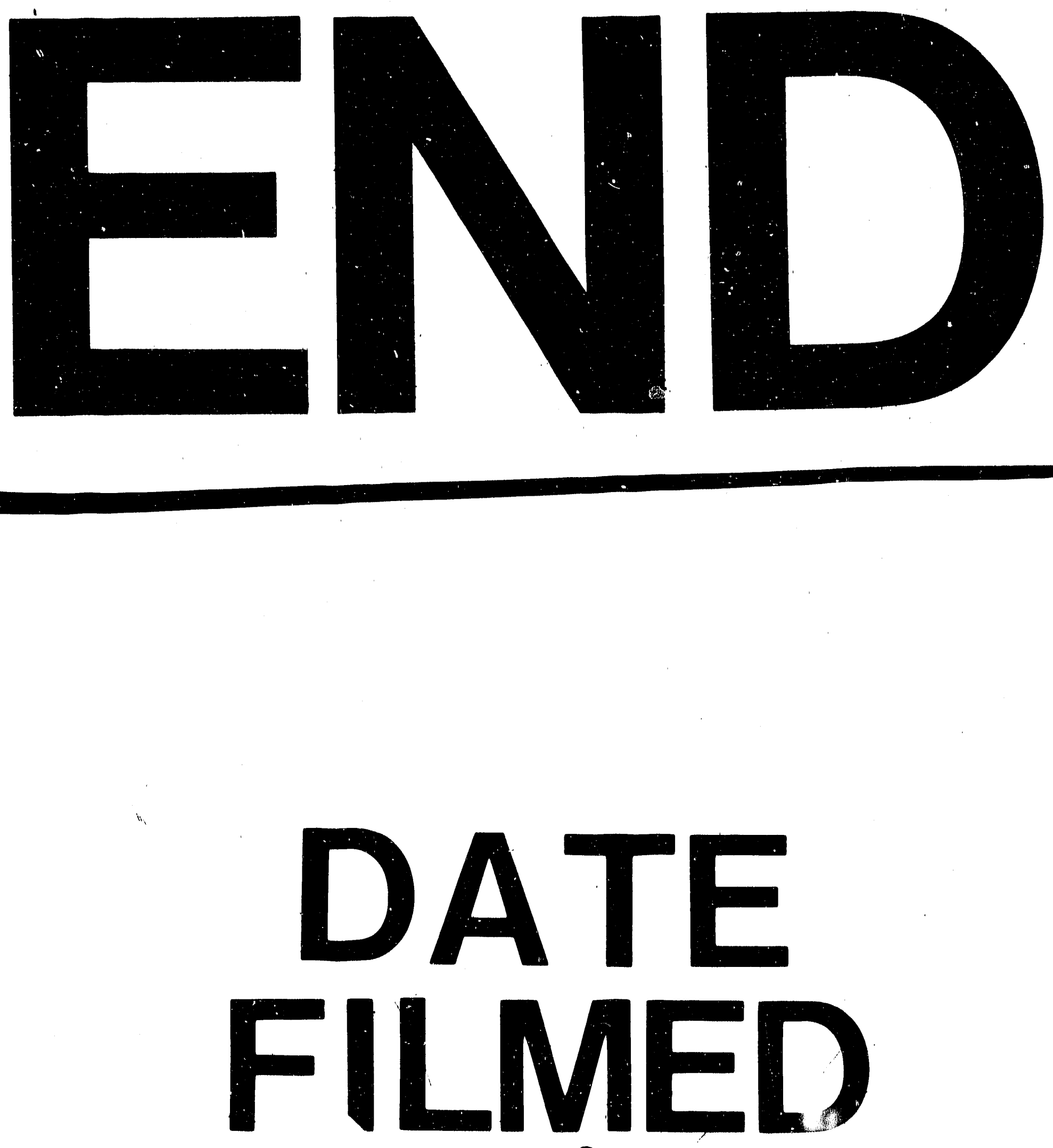

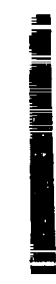

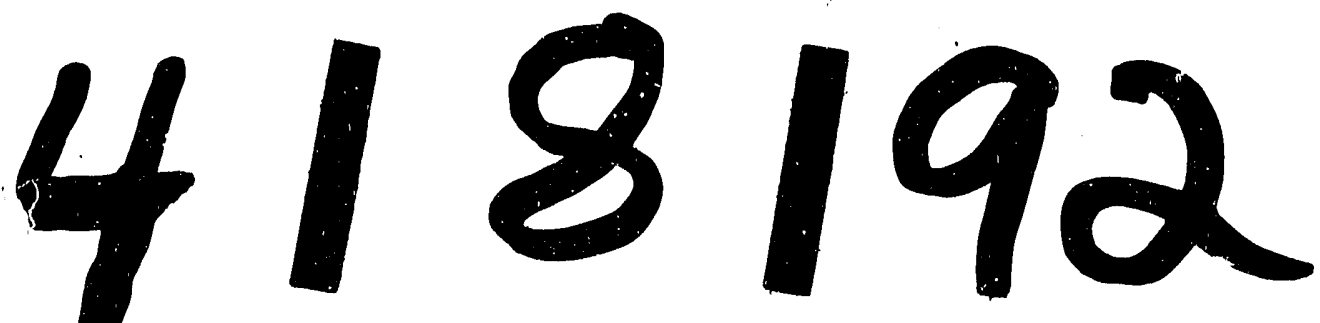

$I$ 
